\title{
Service Quality Assessment: A Study of Consumer Satisfaction in Indian Insurance Sector
}

\author{
${ }^{1}$ Priyanka Anjor, ${ }^{2}$ Prof. S.H.Ali, ${ }^{3}$ Mohnish Kumar, ${ }^{4}$ Vijay Kumar Verma \\ ${ }^{I}$ Faculty MBA, Department IET, Lucknow \\ ${ }^{2}$ KMCUAF, Univ. Lucknow \\ ${ }^{3}$ Faculty MBA, Department IET, Lucknow \\ ${ }^{4}$ Faculty MBA, Department IET, Lucknow
}

\begin{abstract}
The service quality has become a highly instrumental co-efficient in the aggressive competitive marketing. For success and survival in today's competitive environment, delivering quality service is of paramount importance for any economic enterprise. The underlying model of SERVQUAL (Parsuraman et al., 1988) with five dimensions is used to evaluate the impact of service quality on customer satisfaction. The present study aims to measure customers' perception and expectation towards life insurance service quality. Data has been collected from 500 customers from the five cities of Uttar Pradesh (progressive State of India). Besides, the study also investigates the relationship between customer expectation and perception of service quality dimensions and customers overall satisfaction of life insurance service quality.
\end{abstract}

Keywords: Service quality, Life insurance, Perception, expectation, satisfaction.

\section{Introduction}

The liberalization of Indian economy ushered in an era of competitive marketing leading to the radical changes in the entire gamut of products and services. The service sector, limited in nature and scope, changed into an aggressive mode appropriating the front stage touching almost every sphere of human activity, viz., banking, insurance, information technology, welfare etc. and accounted for approximately two-thirds of worldwide GNP right from the beginning of the twenty first century (Kara et al., 2005). Delivering quality service is considered an essential strategy for success and survival in today's competitive environment (Dawkins and Reichheld, 1990; Parasuraman et al., 1985; Reichheld and Sasser 1990; Zeithaml et al., 1990). In the literature, the construct of quality is conceptualized based on perceived service quality (Hishamuddin et al., 2008). Perceived service quality is defined as „global judgment, or attitude, relating to the superiority of the service" (Parasuraman et al., 1988). In the huge service sector, insurance sector is one of the most important entities which has been growing relatively fast in India. At present there are twenty three players in the Indian life insurance industry out of which Life Insurance Corporation is one of the leading public companies, holds largest number of policies in the world to suit different financial requirement of an individual. With a greater choice and an increasing awareness, there is a continuous increase in the customers" expectations and they demand better quality service. Therefore, to sustain in the market, service quality becomes a most critical component of competitiveness for Life Insurance Corporation of India.

The study underscore the need for Life Insurance providers to gear customer service and quality improvement efforts towards components of reliability. Service firms like other organizations are realizing the significance of customer-centred philosophies and are turning to quality management approaches to help managing their businesses. SERVQUAL as an effective approach has been studied and its role in the analysis of the difference between customer expectations and perceptions has been highlighted. Outcomes of the study outline the fact that although SERVQUAL could close one of the important service quality gaps associated with external customer services. The study is based on 500 Life Insurance customers from five major cities of Uttar Pradesh KAVAL (Kanpur, Allahabad, Varanasi, Agra and Lucknow).

Customer service is an integral part of Life Insurance organization. It is necessary to identify the key success factors in Life Insurance industry, in terms of customer satisfaction so as to survive in intense competition and increase the market share. The study will emphasizes the role of improve service quality and hence customer satisfaction. It intends to promote a better theoretical understanding and recognition of the complexities to service quality and its measurement with respect to Life Insurance. Nowadays, Life Insurance companies in Indian compete each other to be a strong and good reputation. The challenge for Life Insurance sector in Indian remains the same that is to bring innovative solutions to client while making them realize the value of those services provided. When clients realize that quality is something that cannot be compromised, an organization has to survive in the competitive market while managing high value service. 


\section{Literature Review}

According to Parasuraman et al, the five dimensions of service quality are reliability, responsiveness, assurance, empathy, and quality of tangibles referred to as SERVQUAL. The SERVQUAL instrument has been the predominant method used to measure consumers' perceptions of service quality. It has five generic dimensions or factors and are stated as follows

1) Tangibles: Physical facilities, equipment and appearance of personnel.

2) Reliability: Ability to perform the promised service dependably and accurately.

3) Responsiveness: Willingness to help customers and provide prompt service.

4) Assurance: (including competence, courtesy, credibility and security). Knowledge and courtesy of employees and their ability to inspire trust and confidence.

5) Empathy: (including access, communication, understanding the customer). Caring and individualized attention that the firm provides to its customers.

Key characteristics of service quality can be difficult to define due to the highly subjective nature of service quality. This is underlined by Deming (1986) when he stated that; quality can be defined only in terms of the agent.' In essence, ultimately this means that it is the consumer that will form a judgement about the quality of any given service that they receive. A further complexity in trying to understand the service quality is its dynamic nature. Firstly, the speed of a consumer's reaction to service quality is immediate, compared, for example, with the speed of reaction to manufactured goods. Additionally, because of the immediacy of the consumer's service quality evaluation, attempting to understand a consumer's reaction to a future service cannot be ascertained today as consumer needs and expectations continually change. Therefore, the relevant characteristics are those which are important to each individual consumer at a specific point of time. (Deming, 1986). This is particularly well summarized by Peters (1985) who stated that; 'consumers perceive service in their own unique, idiosyncratic, emotional, irrational, end-of-the-day, and totally human terms. Perception is all there is.'

Nonetheless, in spite of the intangible, difficult to pin down nature of service quality, what can be concluded is that a good service experience will depend on the organization's ability to understand consumer needs, wants and expectations, and then to deliver service in a way that meets or exceeds those expectations. A service is essentially made up of a package or 'bundle' of goods and services, the production of which will cut across all the traditional organizational lines. Therefore, the responsibility for success will not only lie with manufacturing, but equally with finance, marketing and operations and indeed all the employees of the organization. The development of the optimum service delivery methods therefore needs the whole of the organization to understand both the classification and the characteristics of service and how these relate to their consumer offer.

There has been a considerable research over the past few years, on different aspects of service quality leading to a sound conceptual base for both practitioners and researchers. Authors (Parasuraman et al., 1988; 1991; Carman, 1990) agree that service quality is an abstract concept, difficult to define and measure. On service quality modeling, Gronroos (1984) divides the consumer's perceptions of any particular service into two dimensions, namely technical and functional quality.

Parasuraman et al. (1985) proposed the gap model of service quality that operationalised service quality as the gap between expectation and performance perception of the consumer. Later on, service quality has also been defined broadly as "consumers' assessment of the overall excellence or superiority of the service" (Zeithaml et al., 1993). It is viewed as an attitude or global judgment about the overall excellence of a service, with comparison of expectations and performance as the measuring tools. Researchers have tried to operationalize service quality from different perspectives for different service applications. Based on their conceptual and empirical studies, researchers derived and proposed different service quality dimensions for various service applications. However, the most widely used service quality measurement tools include SERVQUAL (Parasuraman et al., 1988; Boulding et al., 1993) and SERVPERF (Cronin and Taylor, 1992). SERVQUAL scale measures service quality, based on difference between expectation and performance perception of consumers using 22 items and five-dimensional structure. In the SERVPERF scale, service quality is operationalised through performance only score based on the same 22 items and five dimensional structure of SERVQUAL.

\section{Service Quality Measurement}

Several metrics have been used to gauge service quality. In the United States, for example, the industry and state regulators have used "complaint ratios" in this respect (www.ins.state.ny.us). The "Quality Score Card", developed by QIC and RIMS, has also been used. However, both the complaints ratios and the quality scorecards have been found to be deficient in measuring service quality and so a more robust metric is needed.' 
Although service quality structure is found rich in empirical studies on different service sectors, service quality modelling in life insurance services in India is not adequately investigated. Further, for service quality modelling, a set of dimensions is required, but there seems to be no universal dimension; it needs to be modified as per the service in consideration. Thus, the dimensions issue of service quality requires re-examination in context of life insurance services.

\section{Objectives of the Study}

The research is a exploratory study because it will examine perception and expectation of customers in their natural transaction. The objectives are:

$\checkmark \quad$ To study the major factors of service quality that leads to customer satisfaction in Life Insurance Sector.

\section{Research Methodology}

The study is mainly diagnostic in nature. In order to answer the suggested research objectives and test the hypothesis field survey is to be conducted. The sources of the data are mainly primarily and the data are to be collected by questionnaire separately for customers and management.

The present study is conducted in KAVAL region of Uttar Pradesh. There are 500 questionnaires for respondents out of which 498 questionnaires are back.

\section{Profile of Respondents}

The profiles focus on the demographic and economic of respondents. From the table, it shows that out of 500 respondents, $86.6 \%$ of the respondents are male and $13.4 \%$ are female.

The highest education level attained by most of the respondents was Degree (graduate) level (50.8\%), followed by masters $(33.4 \%)$ and Intermediate $(11 \%)$. It shows that majority of respondents were educated with high qualifications. The occupations of respondents were varied. The majority of the respondents were in businessman/self employed (35\%) group, followed by pvt. job (22.6\%), other lawyer (8.2\%), teacher (7.8\%) and housewife $(7.2 \%)$. In term of household income, the majority of respondents were in the income group $3-6$ lacs $(37.8 \%)$, while the second highest group was $6-9$ lacs $(10.6 \%)$.

The result showed that the majority of the respondents choose LIC (66.8\%), followed by ICICI Prudential (10\%), Bajaj Allianz and Max Newyork in same percentage (5.4\%), Tata AIG and Birla Sunlife $(2.8 \%)$. Others (3.6\%), Aviva (2.2\%), Kotak Mahindra (1\%).

Primary- stage sampling units were the respondents who purchased at least one life insurance product in the last three years from any agent and the exact product purchased should have been either a whole life insurance policy and/or an endowment policy. The secondary stage sampling units were markets, shopping malls, institutions and localities of the above mentioned cities. The questionnaires were administered personally to ensure the authenticity of information provided by the respondents.

\section{Validity Analysis}

Content validity: For the present study, the content validity of the instrument was ensured as the service quality dimensions and items were identified from the literature and exploratory investigations, and were thoroughly reviewed by professionals and academicians.

\section{Reliability Test}

The Cronbach's Alpha estimate indicates how highly the items in the questionnaire are interrelated in order to determine reliability of the instrument (Hayes, 1998). Nunnaly (1978) said that the Alpha which is more than 0.7 indicated a high liable.

\section{Data Analysis}

The study is conducted on the basis of 500 respondents; KMO and Bartlett's Test are used for checking the reliability of the questionnaire. This is a measure of multivariate normality of our data set of distribution it is also test whether correlation matrix is an identity matrix. The significant value 0.001 indicate that these data do not produce identical matrix and are thus approximately multivariate normal and acceptable for factor analysis. Customer expectation and perception are measured on seven factors and 23 variables. 


\section{1-customer perception}

KMO and Bartlett's Test

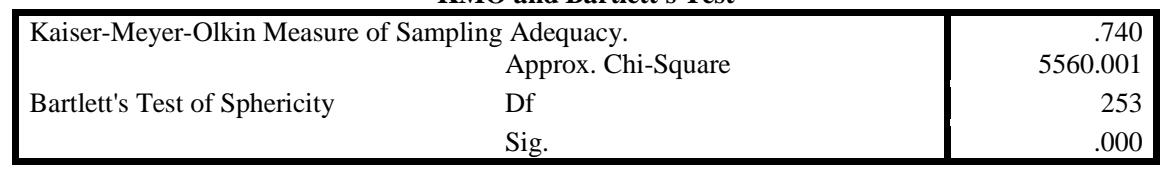

\begin{tabular}{|l|r|r|r|}
\hline \multirow{2}{*}{ Component } & \multicolumn{3}{|c|}{ Initial Eigen values } \\
\cline { 2 - 4 } & Total & \% of Variance & Cumulative \% \\
\hline 1 & 4.177 & 18.159 & 18.159 \\
2 & 3.461 & 15.047 & 33.206 \\
3 & 2.403 & 10.448 & 43.654 \\
4 & 2.198 & 9.556 & 53.210 \\
5 & 1.443 & 6.272 & 59.483 \\
6 & 1.292 & 5.619 & 65.101 \\
7 & 1.118 & 4.860 & 69.961 \\
\hline
\end{tabular}

The table above shows the total variance (in percentage) explained by each of the 7 factors. The cumulative variance of all the factors has come out to be $69.96 \%$ which is better than the expected/desired average of $60 \%$. The system stops the iteration at 7 factors because the \% variance explained by any factor should not go below $1 / 23=4.34 \%$.

Rotated component matrix

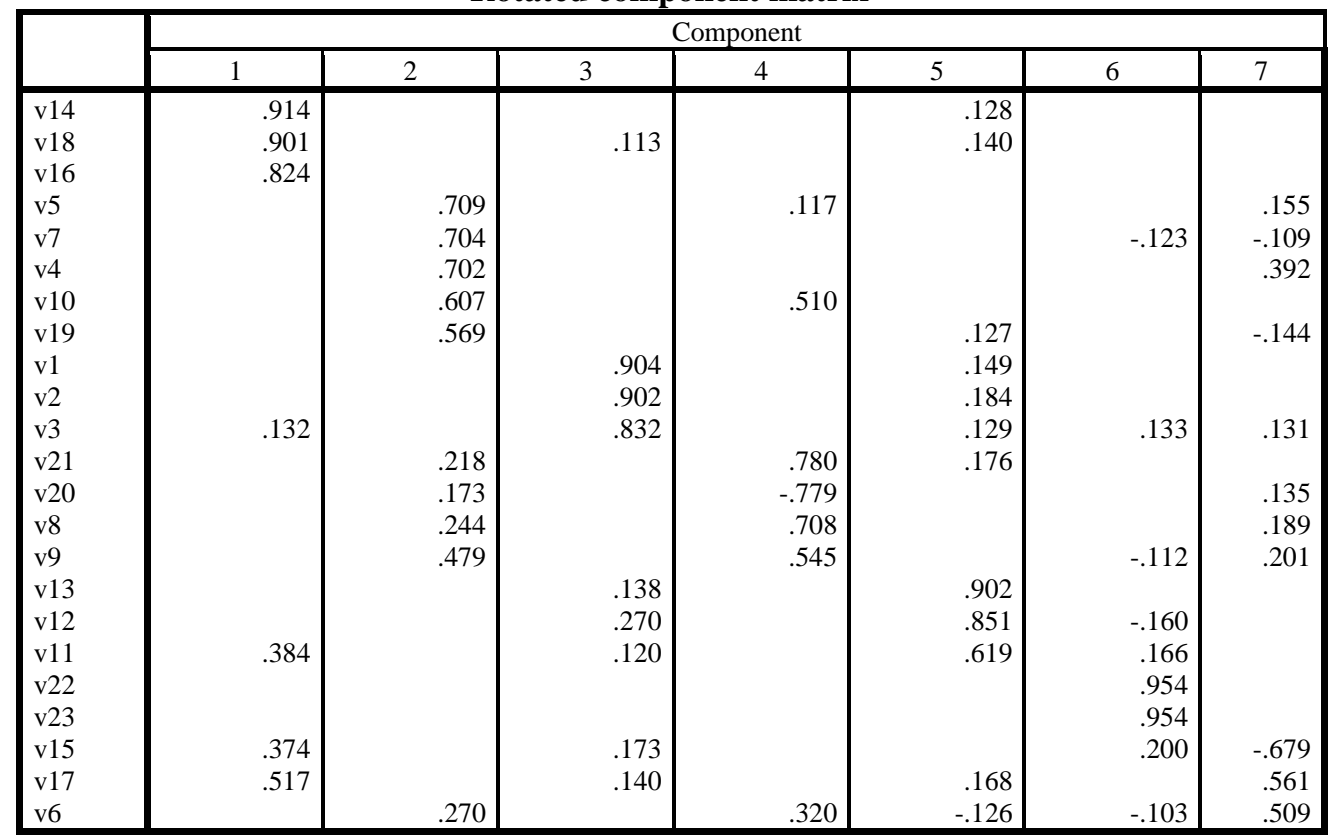

Extraction Method: Principal Component Analysis.

Rotation Method: Varimax with Kaiser Normalization.

a. Rotation converged in 6 iterations.

The table below shows the factor loadings (correlations) of all the 22 variables under study in terms of 7 factors. The factor loadings provide an indication of which original variables are correlated with each factor and the extent of the correlation. This information is used later to identify and label the unobservable factors subjectively.

The table above clubs the data into 7 consolidated factors (from 1-7) but we are still not known as to what all factors form the factor 1 and hence forth, to evaluate the composition and nomenclature of each of this 7 new factors we have do the communality calculation with the help of Eigen values and $\mathrm{H}$ square calculation. The results of the corresponding calculation yield the composition of each of the 7 factors, which are discussed below: 


\section{Findings Based On Perception.}

Factor 1 : The respondents are satisfied with the hidden charges or the administration charges that their insurance company deducts from their premium, and service delightedness from the insurance provider and a complete peace of mind after getting insured from the particular company, are the first factor that are consider to be most important factor from the study.

Factor 2: The second important factor is about information of the new plans/initiatives of the company by the agents/financial advisors and the Management officials show a sincere interest in solving the problems of customer.

Factor 3: The employees are courteous \& offer the personal attention the customer need from them which helps them in taking decisions.

Factor 4: modern surrounding and tangibility factor as well as service delivery aspect is fourth important factor that is important for customers.

Factor 5: feel safe in your premiums with your insurance company and the same service as shown in the advertisements in TV and news papers that is communication gap forms the fifth important factor in insurance sector.

Factor 6: the behavioural aspect of agents is considered to be the sixth important factor.

Factor 7: Claim settlement process is very transparent and there are no hassles are the seventh important factor. Thus we can see that most of the factors are a combination of more than one factor.

\section{Customer Expectation}

\begin{tabular}{|c|c|c|c|c|c|c|c|}
\hline \multicolumn{2}{|l|}{ Principle component matrix } \\
\hline \multirow{2}{*}{ variables } & \multicolumn{7}{|c|}{ Component } \\
\cline { 2 - 9 } & 1 & 2 & 3 & 4 & 5 & 6 & 7 \\
\hline v28 & .967 & & & & & & \\
\hline v27 & .922 & -.147 & .107 & & & & \\
\hline v29 & .849 & & & .264 & & .157 & \\
\hline v31 & .812 & -.122 & & .253 & & & \\
\hline v26 & .688 & .341 & & -.261 & & & \\
\hline v37 & & .906 & & .111 & & -.103 & \\
\hline v38 & & .874 & .181 & .151 & & & \\
\hline v36 & & .871 & & & -.153 & & \\
\hline v32 & & -.570 & & -.172 & & -.216 & .251 \\
\hline v41 & .108 & & .977 & & & & \\
\hline v39 & .108 & & .977 & & & & \\
\hline v40 & & -.244 & .858 & -.121 & .113 & & \\
\hline v43 & -.261 & .459 & .582 & .178 & & & \\
\hline v42 & .151 & .320 & .424 & -.304 & & -.121 & -.211 \\
\hline v33 & & .159 & & .904 & & .171 & \\
\hline v34 & .109 & .218 & & .864 & & & \\
\hline v35 & & & & .850 & & -.209 & \\
\hline v30 & .431 & .122 & & .639 & & .293 & \\
\hline v25 & & -.111 & & & .977 & & \\
\hline v24 & & -.109 & & & .974 & & \\
\hline v44 & & & & & & .236 & .794 \\
\hline Extraction Method: Principal Component Analysis. & & & \\
\hline Rotation Method: Varimax with Kaiser Normalization. & & & \\
\hline a. Rotation converged in 6 iterations. & & & & \\
\hline
\end{tabular}

Customer expectation

\begin{tabular}{|c|c|}
\hline $\begin{array}{r}\text { Kaiser-Meyer-Olkin Measure of Sampling Adequacy. } \\
\text { Approx. Chi-Square }\end{array}$ & $\begin{array}{r}.740 \\
5560.001\end{array}$ \\
\hline Bartlett's Test of Sphericity & 253 \\
\hline Sig. & .000 \\
\hline
\end{tabular}

This is a measure of multivariate normality of our data set of distribution it is also test whether correlation matrix is an identity matrix. The significant value 0.001 indicate that these data do not produce identical matrix and are thus approximately multivariate normal and acceptable for factor analysis. 
The table above shows the total variance (in percentage) explained by each of the 22 factors. The cumulative variance of all the factors has come out to be $77.42 \%$ which is better than the expected/desired average of $60 \%$. The system stops the iteration at 7 factors because the $\%$ variance explained by any factor should not go below $1 / 23=4.34 \%$.

\section{Rotated Component Matrix}

The table below shows the factor loadings (correlations) of all the 22 variables under study in terms of 6 factors. The factor loadings provide an indication of which original variables are correlated with each factor and the extent of the correlation. This information is used later to identify and label the unobservable factors subjectively.

The table above clubs the data into 6 consolidated factors (from 1-6) but we are still not known as to what all factors form the factor 1 and hence forth, to evaluate the composition and nomenclature of each of this 6 new factors we have do the communality calculation with the help of Eigen values and H square calculation. The results of the corresponding calculation yield the composition of each of the 6 factors, which are discussed below:

\begin{tabular}{|l|r|r|r|}
\hline \multirow{2}{*}{ Component } & \multicolumn{3}{|c|}{ Initial Eigenvalues } \\
\cline { 2 - 4 } & Total & \% of Variance & Cumulative \% \\
\cline { 2 - 4 } & 4.653 & 20.232 & 20.232 \\
\hline 1 & 3.612 & 15.705 & 35.937 \\
2 & 3.384 & 14.714 & 50.651 \\
3 & 2.313 & 10.058 & 60.709 \\
4 & 1.720 & 7.478 & 68.187 \\
5 & 1.073 & 4.666 & 72.853 \\
6 & 1.052 & 4.576 & 77.428 \\
7 & & & \\
\hline
\end{tabular}

\section{Findings based on expectation}

Factor 1: V28, Management officials of your insurance company are never too busy to respond to your request.

$\checkmark$ V27, you are well informed about the new plans/initiatives of the company by the agents/financial advisors.

$\checkmark \quad$ V29, when you have a problem, the Management officials show a sincere interest in solving it.

$\checkmark$ V31, Your insurance provider has $24 X 7$ customer support service and they are very responsive.

$\checkmark$ V26 The eagerness of agents/financial advisors of the company is same before and after getting insured.

$\checkmark \quad$ All of the above factors are considered as most important factors, but empathy is considered to be most valued, because every consumer wants to be delighted by the management officials.

Factor 2: V37, Claim settlement process is very transparent and there are no hassles.

$\checkmark \quad$ V38, you get a complete peace of mind after getting insured from the particular company.

$\checkmark$ V36, you are satisfied with the hidden charges or the administration charges that your insurance company deducts from your premium.

V32, Your insurance provider has wide range of plans according to your needs or

requirements.

Since these components talk about the ability of the service provider to perform service dependably and efficiently and also about their willingness to provide hassle-free and prompt services. So, this factor can be labelled as 'competence'.

Factor 3: V41, if given a chance would you like to switch over to another insurance company?

$\checkmark \quad$ V39, you are satisfied with the service you receive from the insurance provider.

$\checkmark$ V40, you are delighted with the service you receive from the insurance provider.

$\checkmark$ V43, Moderns of office Surroundings

$\checkmark \quad$ V42 Will you recommend anyone else to buy insurance policy from this company; because of the service quality of your insurance provider. 
All the above are the third important factor. Since all these components are related to use of modern aids in providing service. So, this factor can be labeled as 'technology'

Factor 4: V33, You get the same service as shown in the advertisements in TV and newspapers.

$\checkmark \quad$ V34, Premium paying options are very flexible and convenient.

$\checkmark \quad$ V35, you feel safe in your premiums with your insurance company.

$\checkmark \quad$ V30, Your insurance company has convenient branch locations. All the above are the fourth important factor, these factors are related to accessibility in providing services.

Factor 5: V25, Agents of your insurance provider are very true to their words and never conceal the facts.

V24, The behaviour of agents/financial advisors helps you in taking decision.

All the above the fifth important factor. All these components are related to creating an overall image of the organization in the eyes of the customers. So, this factor can be labelled as 'corporate image'.

Factor 6: V44, Moderns of physical facilities that are tangibility is considered to be the last factor in terms of customer expectation.

Thus we can see that most of the factors are a combination of more than one factor. Since all these components are related to providing physical facilities and communication materials. So, this factor can be labelled as 'tangibles'.

\section{Conclusion}

From the above analysis we conclude that the expectation are higher than perception in terms of service quality in insurance sector, that is communication gap and service delivery aspect is the most important factor in terms of customer expectation, therefore these factors need to be reviewed. It has been analysed that seven factors are from customer perception and six factors are for customer expectation. The research resulted in the development of a reliable and valid instrument for assessing customer perceived service quality for life insurance services. In the competitive insurance sector, these findings can be transformed into effective strategies and actions for achieving competitive advantage through customer satisfaction and retention.

Although this study focuses on life insurance industry in India, however the results and recommendations of this paper can be used for service quality improvements of life insurance industries of other countries as well. This can be performed by incorporating necessary changes in service quality aspects in accordance with socio-economic environment of that nation. There are, some scope for further research. Future studies in this area should also measure changes in service quality expectations over time in order to have a better understanding of how perceptions about service quality relate to satisfaction and loyalty. This is because service expectations and perceptions are known to be affected by customers' immediate reaction to specific service encounters. The results confirm that service quality is crucial to acquire loyal consumers, as well as the influence of service convenience on consumer loyalty. In addition, several implications for insurance providers are given resulting from our analysis. The result indicates that improved service convenience is successful in turning consumers into loyal consumers. Service providers realize well the positive influence of convenience on consumer value and loyalty. Moreover, Colwell (2008) mentioned that in homogeneous markets, where service providing was similar as well as not main competitive source. Hence, once service providers provide greater service convenience, they would benefit more and earn competitive advantage.

\section{Managerial Implications}

In light of the reseach conclusions, four managerial suggestions for insurance service providers might elevate the consumer satisfaction and maintain a good consumer relationship:

1. Provide Various Customised Services to Satisfy Consumers' Needs.

The key to the success of insurance services is their various functions and services. For the studied insurance service providers, it should emphasize the core services to be customised as per the needs of specific group of consumers.

2. Improve Visible and Invisible Quality of Services and employees.

Consumer satisfaction and consumer loyalty are related to consistent marketing. Businesses should improve not only the overall quality of service, but also consumer service personnel's professional knowledge in financial merchandises and communication. A better service is accompanied by a better consumer relationship and a higher consumer satisfaction.

3. Employee empowerment leads to better consumer education which ultimately leads to consumer satisfaction.

insurance service providers must concentrate on behavioural aspect of service quality that is employees who directly deals with the consumers must be trained and empowered to educate consumers. Better consumers education will lead to efficient service delivery and it is certainly going to give satisfaction to consumers 
and will also help to retain them. These services will surely attract some new consumers and will make existing consumers loyal.

4. Minimisation of the GAPS existing in service quality.

Without identifying the gaps existing in service quality, it will be difficult to maintain quality. Insurance service providers must identify the gaps by doing continuous research on consumers' expectations and perception for service quality and management's expectations and perception for service quality. Insurance service providers have to ensure the corrective measures to minimise the existing gaps.

\section{References}

[1] Adam, K., Johanson, and M., Gravesen, I., 1995, Service Productivity: A Vision or a Search for a New Outlook, paper presented at The Ninth World Productivity Congress, Istanbul.

[2] Berry, L.L., Bennett, D.R., and Brown, C.W., 1989, Service Quality. A Profit Strategy for Financial Institutions, Irwin, New York, NY.

[3] Berry, L.L., Zeithaml, V.A., and Parasuraman, A., 1985, Quality Counts in Services Too, Business Horizons, 44-52.

[4] Bitner, M.J., 1990, Evaluating Service Encounters: The Effects of Physical Surroundings and employee Responses, Journal of Marketing, 54, 69-82.

[5] Cowell, D., 1998, The Marketing of Services, London.

[6] D.E. Brown, S.W., Advances in Services Marketing and Management, Greenwich, CT, 177- 205.

[7] Economic Report 2006/2007, Insurance Industry, Volume 31, Ministry of Finance, Malaysia.

[8] Garvin, D.A., 1988, Managing Quality, the Free Press, New York, NY

[9] Gronroos, C., 1984, A Service Quality Model and its Marketing Implications, European Journal of Marketing, 18, 35-44.

[10] Gronroos, C., 1998, assessing Competitive Edge in the New Competition of the Service Economy: The Five Rules of Service, Working Paper No.9, First Interstate Centre for Services Marketing, Arizona State University.

[11] Gummesson, E., 1992, Quality Dimensions: What To Measure In Service Organisation, Swartz, T.A., Bowen, 